\title{
Pre-energize Analysis on 3 Phase Transformer by Considering Each Phase Flux
}

\author{
Hadwim Septiawan, I Made Yulistya Negara, Feby Agung Pamuji \\ Electrical Engineering Departement \\ Sepuluh Nopember Institute of Technology \\ Surabaya, Indonesia \\ E-mail: hadwims77@gmail.com, yulistya@ee.its.ac.id, feby@ee.its.ac.id
}

\begin{abstract}
Inrush current is a transient phenomenon that occurs when a transformer is first energized to a voltage source at no-load conditions. It causes a very high inrush current. Inrush currents can adversely affect the electric power system and can cause improper work of a relay protection errors. The purpose of this study is to determine the amount of inrush current and minimize the amount of inrush current by using the pre-fluxing method.

In this study, a test was carried out using a 3-kVA core type 3 phase transformer. This test is done by giving DC flux before the transformer is connected to the voltage source, then the three transformer phases are energized simultaneously at a certain voltage angle so that the inrush current may could be minimized. The test results show that the transformer that is given a DC flux always has a relatively small inrush current. In this test the inrush current is reduced to a minimum value at an ignition angle of 90 degrees with an inrush current value of 0.74 $A$ in phase R, 3.41 $\mathrm{A}$ in phase $\mathrm{S}$, and $3.80 \mathrm{~A}$ in phase $\mathrm{T}$.
\end{abstract}

Kata kuncu_Inrush Current, Transformer, Flux, Transient

\section{INTRODUCTION}

The Role of a transformer as an electrical component, absolutely, could not be neglected in an electric power system, so its reliability must be maintained. A phenomenon that should be overcome during it energize is a phenomenon called inrush current. Inrush current is a transient phenomenon that can affect the reliability of the transformer mechanically and electrically, because it's very high value. It also can cause operating errors in the differential and over current relays of transformer. Transformers that often go through an energize process are also more prone to failing isolation [1].

The main cause of inrush current is saturation of the transformer magnetic core. Uncontrolled energize process can cause the transformer to work at a high saturation level so that a high transient current value can appear [2]. When the transformer is first connected to a voltage source, the amount of inrush current can be valued up to 10-20 times that of the nominal current of the transformer [3]. The process of charging repeatedly or energizing the transformer without a load can cause isolation failure in the transformer, this proves that the surge current has a bad impact on the transformer so the inrush current must be considered when energizing the transformer [1].

The method used in this study is to determine the value of the magnetization inductance of the transformer, then design a pre-energize component consisting of a capacitor that will provide DC flux to the transformer before the energy process is carried out. Testing is done by giving flux to the transformer when off and energized with a predetermined voltage angle [4]. Data obtained from this test will be analyzed, so that conclusions can be drawn.

\section{INRUSH CURRENT}

Inrush current is a transient phenomenon that occurs when electrical equipment that has the principle of electromagnetic work is energized with a voltage source in the off state [7]. Inrush currents can occur in electrical equipment such as transformers and motors. When the transformer is energized for the first time in a no-load state, the transformer will draw a current that reaches 20 times the nominal current and the duration of the inrush current can reach up to 0.5 seconds [1]. Inrush currents can cause various problems in the power system such as faulty operation of relay operations, failure of transformer isolation, shortening equipment life, harmonics problems, and others. Examples of graphs inrush current values can be seen in Fig 1 .

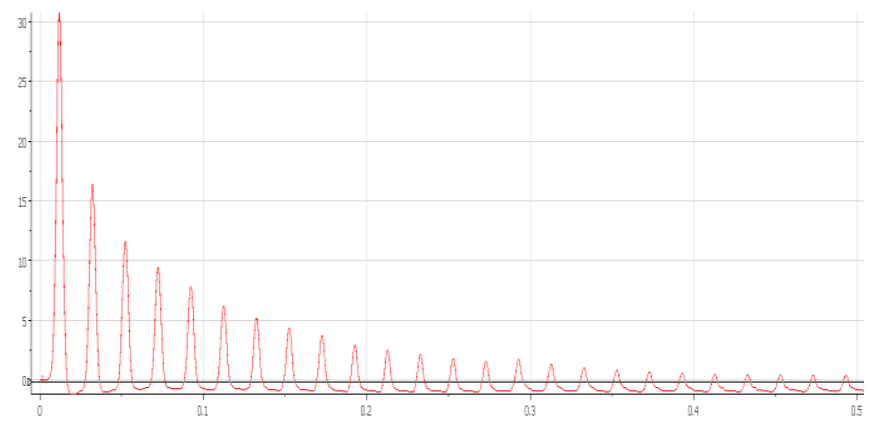

Fig 1. Inrush Current Graph

One of the main causes of inrush current is saturation of the transformer magnetic core [8]. Transformer magnetic core saturation is caused by sudden changes in system voltage due to switching transients, generators that are out of sync, external noise and disturbance restoration [1].

Inrush currents are more common than short circuits, so inrush currents must be followed up further. There is no definite evidence that when energizing the transformer process can cause interference caused by high inrush currents. However, transformers that experience isolation problems because they are often energized under no-load conditions show that the inrush current has a dangerous effect. The problem that often occurs due to energizing the transformer is the problem of the stability of the system around the transformer which triggers overvoltage and resonance phenomena [1].

The magnitude of the inrush current value is influenced by various things, one of which is the ignition angle. The magnitude value of the inrush current will be the maximum value when energized with the ignition angle of 0 degrees, 
and will be the minimum value when energized with the ignition angle of 90 degrees [9].

Inrush current is influenced by internal factors and external factors. The internal factor of the inrush current is influenced by the characteristics of the transformer core material. Whereas the external factor of the inrush current is influenced by the residual flux remaining in the transformer core. The residual flux value that is not in accordance with the instantaneous flux value in a steady state will trigger an inrush current [10].

In the inrush current, it consists of magnetization current and core loss current. The magnetization current is the current needed to produce flux in the transformer core so the transformer can work. Meanwhile, the core loss current is the current needed for hysterical losses and Eddy current losses. Therefore, the inrush current is needed by the transformer to fill the flux in order to operate.

\section{METHODOLOGY OF INRUSH FLOW REDUCTION WITH PRE ENERGIZE}

Inrush current reduction test in this study is done by giving the DC flux to the transformer. The pre-energize component used is in the form of capacitors and diodes, the capacitors will then be charged according to the specified voltage, and then discharge will be carried out on two transformer phases namely the $\mathrm{S}$ and $\mathrm{T}$ phases (as in Fig 2). The flux filling step is carried out when the transformer is off. After the flux charging stage is completed, the energize process will be carried out on the transformer, the energize process is carried out by looking at the voltage ignition angle of one of the phases that is not carried out, namely the $\mathrm{R}$ phase.

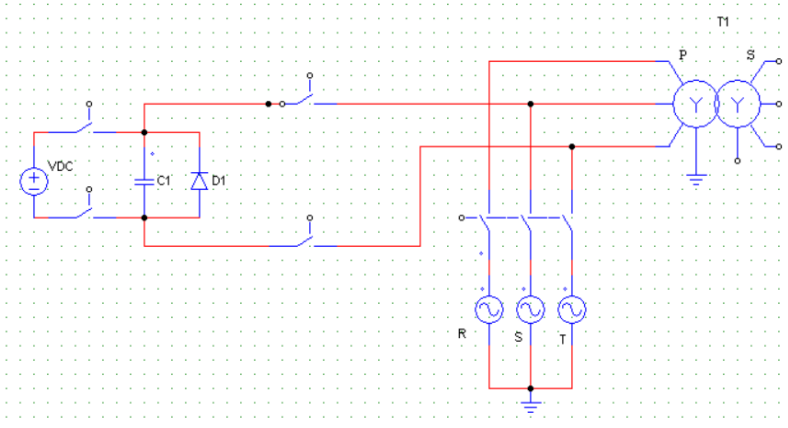

Fig 2. Reduction Current Inrush by Pre-energize

In this test, demagnetization is also performed by using demagnetization capacitors. The purpose of demagnetization is to remove the residual flux found in the transformer, so that the measurement of inrush currents can be more appropriate and accurate. Demagnetization is done by connecting the transformer in a state of no voltage after being energized with a demagnetization capacitor so that the remaining flux in the transformer can be drained into the demagnetizing capacitor. The time needed to dispose of the remaining flux in the transformer by demagnetizing varies, in this test demagnetization is carried out for approximately 3 minutes to obtain more accurate inrush current data. Demagnetization scheme can be seen in Fig 3.

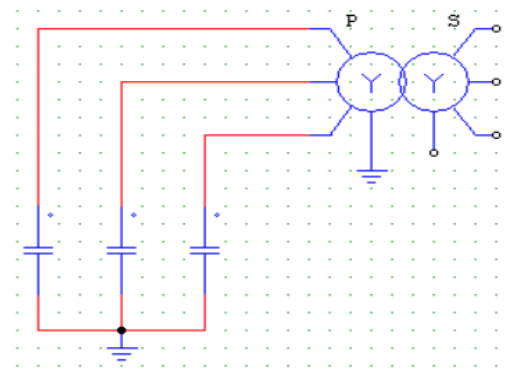

Fig 3. Demagnetization Scheme

Demagnetization capacitors are used as a means of emptying the residual flux in the transformer. The purpose of demagnetization is to empty the residual flux on the transformer after going through the energize process, which will have an impact on the accuracy of the data taken from each test. Demagnetization is done when the transformer is turned off after going through the energy process, with a predetermined time. A manual switch is used for the demagnetization of the transformer.

\section{PRE-ENERGIZE COMPONENT}

In this study, we need a component that acts as a DC filler flux in the transformer to reduce the amount of inrush current when energized, therefore a pre energize device is designed to fill the DC flux in the transformer. The pre energize device consists of a capacitor and a diode, where the capacitor is charged with a certain voltage and then discharged to fill the flux in the transformer. The diode has a role to prevent reverse charging from the transformer after being filled with flux, so that the capacitor will automatically be isolated. The series of pre energize devices can be seen in Fig 4.

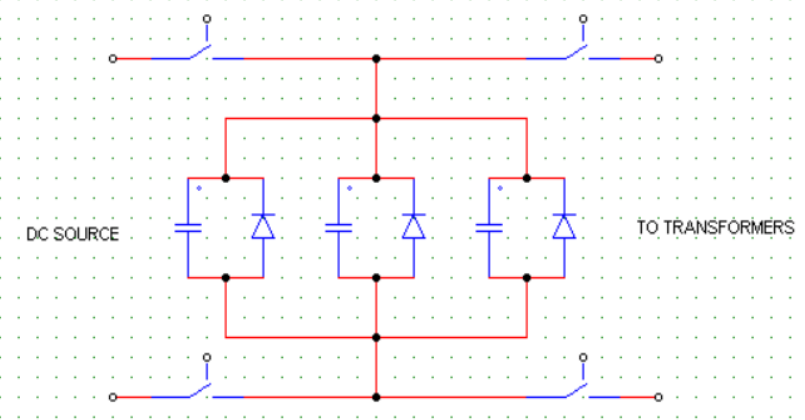

Fig 4. Pre-energize Tools

This tool uses a diode with a current rating of $10 \mathrm{~A}$. Whereas the value of a capacitor is determined by how much DC voltage is used to charge a capacitor. In this test a DC voltage of $5 \mathrm{~V}$ is used to fill the capacitors. According to studies [11] the capacitor value is determined from the following equation:

$$
C=\left(\frac{1}{L_{m_{\text {approx }}}}\right)\left(\frac{\sqrt{2} V_{L N}}{2 \pi f \times V_{D C}}\right)^{2}
$$


Where $L_{m_{\text {approx }}}$ is the transformator magnetization inductance, $V_{L N}$ line-to-neutral voltage, and $V_{D C}$ is the capacitor charging voltage. According to studies value [11] $L_{m_{\text {approx }}}$ is determined from the following equation:

$$
L_{m_{\text {approx }}}=\frac{V_{L N}{ }^{2}}{2 \pi f \times 0.05 S_{\text {rated }}}
$$

Where $S_{\text {rated }}$ is the transformer power capacity rating. From the above equation, the $L_{m_{\text {approx }}}$ value of $1,037 \mathrm{H}$ is obtained, then this value is substituted into equation 3.1 and the required capacitor value is $31.7 \mathrm{mF}$, with a $V_{L N}$ value of $220 \mathrm{~V}$ and $\mathrm{f}$ of $50 \mathrm{~Hz}$. Therefore, in this study a $30 \mathrm{mF}$ capacitor was used.

The energy stored in the capacitors is obtained from the following equation:

$$
E=\frac{1}{2} C \times V_{D C}^{2}
$$

From equation 3 , the value of $\mathrm{E}$ is $0.375 \mathrm{~J}$. The capacitor receives a supply power of $0.015 \mathrm{~W}$, so the time required for charging the capacitor is

$$
t_{\text {charge }}=\frac{E}{P_{\text {Supply }}}=25 \mathrm{~s}
$$

From the above equation, it takes charging time for 25 seconds.

\section{TEST RESULTS}

Tests are carried out on a $3 \mathrm{kVA} 3$-phase no-load test transformer with $\mathrm{Y}-\mathrm{Y}$ winding configuration by changing the voltage angle between 0, 60 and 90 degrees. Tests carried out with due regard to two conditions, namely without pre energize and by using pre energize before the transformer is given a voltage.

This test is carried out using a current transformer in each phase and then the secondary side of the current transformer is connected to the DAQ 4296 data acquisition hardware. The DAQ 4296 data acquisition device will be connected to the computer through LabVIEW software which will display the results of the measurement of inrush currents recorded by DAQ 4296. Furthermore, DIAdem software will be used to process the data displayed by LabVIEW.

\section{A. Test Results Using Zero Degree Ignition Angle}

Test 1 is carried out at an angle of voltage ignition of 0 degrees. The test transformer will be demagnetized for 3 minutes for each data collection. In the condition without pre-energizing the transformator is immediately energized after the demagnetization process is carried out to measure the amount of inrush current. In the condition of using the pre energize transformer will be given an initial DC flux using a pre energized component that has been charged, charging the flux is done after the demagnetization process. The process of stabilizing this data is done 5 times both in conditions without pre-energize and conditions using preenergize.
One of the measurement results of testing at 0 angle can be seen in Fig 5. While the data from the test results can be seen in table 1.

Table 1. Zero Degree Ignition Without Pre-energizing vs Pre-energizing

\begin{tabular}{|c|c|c|c|c|c|c|}
\hline \multirow{2}{*}{ Tests } & \multicolumn{3}{|c|}{$I_{\text {inr }}(\mathrm{A})$} & \multicolumn{3}{|c|}{$I_{\text {pre }}(\mathrm{A})$} \\
\cline { 2 - 7 } & $\mathrm{R}$ & $\mathrm{S}$ & $\mathrm{T}$ & $\mathrm{R}$ & $\mathrm{S}$ & $\mathrm{T}$ \\
\hline 1 & 34.09 & 10.22 & 4.92 & 32.31 & 4.22 & 3.86 \\
\hline 2 & 31.01 & 10.63 & 5.51 & 31.28 & 4.32 & 3.34 \\
\hline 3 & 33.50 & 9.58 & 5.69 & 33.61 & 4.15 & 3.69 \\
\hline 4 & 32.81 & 9.71 & 4.60 & 30.77 & 4.05 & 3.73 \\
\hline 5 & 32.02 & 11.82 & 4.63 & 28.82 & 3.95 & 3.35 \\
\hline
\end{tabular}

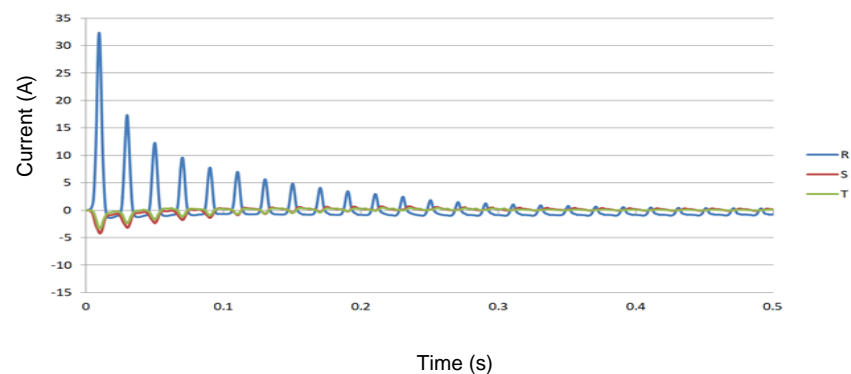

Fig 5. Inrush Current using zero angle ignition with pre energize

From Table 1 it can be seen that the condition without pre energize, the highest current value is in the phase of $\mathrm{R}$ with an average value of $32.69 \mathrm{~A}$. This is because the $\mathrm{R}$ phase voltage value is at 0 so that the transformer will attract a larger inrush current, while for phase $S$ the average value of inrush current is $10.39 \mathrm{~A}$ and for phase $\mathrm{T}$ the average value of inrush current is $4.14 \mathrm{~A}$. If you see the average value of inrush current for both phases $\mathrm{S}$ and $\mathrm{T}$ is far below the average value of inrush current from the $\mathrm{R}$ phase, this is because the phases $S$ and $T$ have a voltage value that is greater than the $\mathrm{R}$ phase so that the inrush current produced by the $\mathrm{S}$ and $\mathrm{T}$ phases is smaller than the $\mathrm{R}$ phase.

B. Test Results Using 60 Degree Ignition Angle

Test 2 is carried out at a voltage angle of 60 degrees. The transformer will be demagnetized for 3 minutes for each data collection. In the condition without pre energizing the transformer is immediately energized after the demagnetization process is carried out to measure the amount of inrush current. In the condition of using preenergize, the transformer will be given an initial DC flux using a pre-energized component that has been charged, and flux charging will be carried out after the demagnetization process. The process of stabilizing this data is done 5 times both in conditions without pre-energize and conditions using pre-energize.

One of the test measurement results at the starting point of this 60 can be seen in Fig 6 . While the test result data can be seen in table 2. From table 2 it can be seen that in the condition without pre energizing the highest current value is in phase $\mathrm{T}$, with an average value of $28.22 \mathrm{~A}$, because in phase $\mathrm{T}$ the voltage value is at a minimum value so that the transformer will attract a larger inrush current, whereas for phase $\mathrm{R}$ the average value of inrush current is $3.89 \mathrm{~A}$ and for phase $\mathrm{S}$ the average value of inrush current is $4.78 \mathrm{~A}$. 
Table 2. Sixty Degree Ignition with Pre-energize and without Pre-energize

\begin{tabular}{|c|c|c|c|c|c|c|}
\hline \multirow{2}{*}{ Tests } & \multicolumn{3}{|c|}{$I_{\text {inr }}(\mathrm{A})$} & \multicolumn{3}{c|}{$I_{\text {pre }}(\mathrm{A})$} \\
\cline { 2 - 7 } & $\mathrm{R}$ & $\mathrm{S}$ & $\mathrm{T}$ & $\mathrm{R}$ & $\mathrm{S}$ & $\mathrm{T}$ \\
\hline 1 & 3.68 & 4.82 & 26.55 & 1.34 & 2.95 & 10.68 \\
\hline 2 & 4.13 & 4.26 & 30.04 & 1.86 & 2.15 & 11.22 \\
\hline 3 & 4.07 & 4.81 & 29.25 & 1.91 & 2.13 & 10.89 \\
\hline 4 & 4.16 & 4.74 & 29.70 & 1.94 & 2.30 & 10.30 \\
\hline 5 & 3.47 & 5.28 & 25.55 & 1.83 & 2.51 & 10.42 \\
\hline
\end{tabular}

When seen the average value of inrush current for both phase $\mathrm{R}$ and $\mathrm{S}$ is far below the average value of inrush current from the $\mathrm{T}$ phase, this is because the phase $\mathrm{R}$ and $\mathrm{S}$ have a voltage value that is greater than the $T$ phase so that the inrush current generated by the $\mathrm{R}$ and $\mathrm{S}$ phases is smaller than the $\mathrm{T}$ phase.

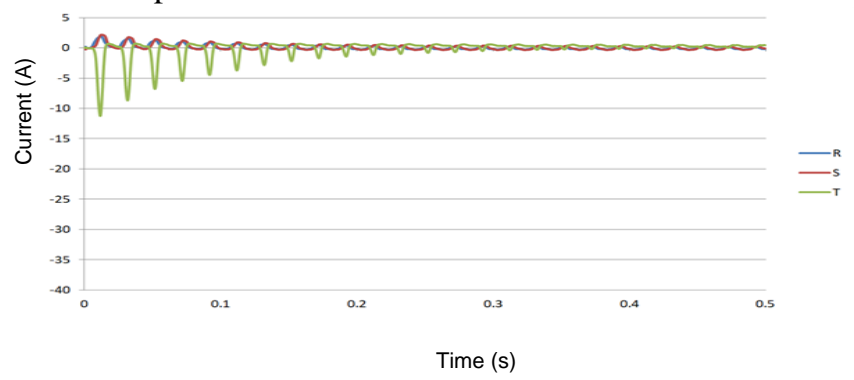

Fig 6. Sixty Degree Ignition with Pre-energize

\section{The testing results using 90 degrees ignition angle}

Test 3 is carried out at an angle of voltage ignition at 90 degrees. The test transformer will be demagnetized for 3 minutes for each data collection. In the condition without pre energizing the transformer is immediately energized after the demagnetization process is carried out to measure the amount of inrush current. In the condition of using the pre energize transformer will be given an initial DC flux using a pre energized component that has been charged, charging the flux is done after the demagnetization process. This data retrieval process is carried out 5 times both in conditions without pre-energize and conditions using pre-energize.

One of the measurement results of the test at the ignition angle of 90 can be seen in Fig 7. While the test results can be seen in table 3.

Table 3. Ninety Degree Ignition with Pre-energize and without Pre-energize

\begin{tabular}{|c|c|c|c|c|c|c|}
\hline \multirow{2}{*}{ Tests } & \multicolumn{3}{|c|}{$I_{\text {inr }}(\mathrm{A})$} & \multicolumn{3}{c|}{$I_{\text {pre }}(\mathrm{A})$} \\
\cline { 2 - 7 } & $\mathrm{R}$ & $\mathrm{S}$ & $\mathrm{T}$ & $\mathrm{R}$ & $\mathrm{S}$ & $\mathrm{T}$ \\
\hline 1 & 3.41 & 32.12 & 32.16 & 0.71 & 3.72 & 3.57 \\
\hline 2 & 2.89 & 32.52 & 31.23 & 0.70 & 3.69 & 3.48 \\
\hline 3 & 3.97 & 34.61 & 34.41 & 0.75 & 3.12 & 4.14 \\
\hline 4 & 3.81 & 32.45 & 32.83 & 0.81 & 3.47 & 3.78 \\
\hline 5 & 3.45 & 33.11 & 32.15 & 0.74 & 3.03 & 4.02 \\
\hline
\end{tabular}

From table 3 it can be seen that in the condition without pre energizing the lowest current value is in phase $\mathrm{R}$ that is with an average value of $3.51 \mathrm{~A}$, this is because in phase $\mathrm{R}$ the voltage value is at the maximum value so that the transformer will draw a minimum inrush current, whereas for phase $\mathrm{S}$ the average value of inrush current is $32.96 \mathrm{~A}$ and for phase $\mathrm{T}$ the average value of inrush current is $32.56 \mathrm{~A}$.

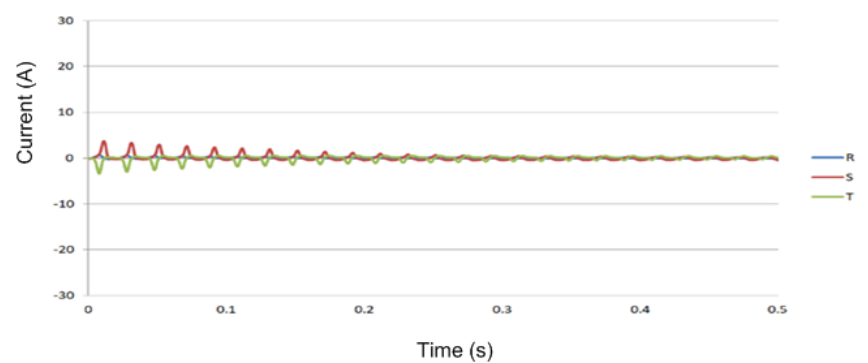

Fig 7. Ninety Degree Ignition with Pre-energize

If you see the average value of inrush current for both phases $\mathrm{S}$ and $\mathrm{T}$ is far above the average value of inrush current from the $\mathrm{R}$ phase, this is because the phases $\mathrm{S}$ and $\mathrm{T}$ have a voltage value that is smaller than the $T$ phase so that the inrush current produced by the $\mathrm{S}$ and $\mathrm{T}$ phases is greater than the $\mathrm{R}$ phase.

\section{CONCLUSION}

After testing the inrush current reduction on a $3 \mathrm{kVA} 3$ phase transformer using the pre energize method, three tests were performed with different ignition angles of 0,60 , and 90 degrees, several conclusions can be drawn as follows:

1. The ignition angle is one of the things that determines the size and size of the inrush current in the transformer. The ignition angle of 0 degrees in each phase (minimum voltage) will produce a large inrush current value in phase $\mathrm{R}$ with an average value of $32.69 \mathrm{~A}$. While the ignition angle of 90 degrees in each phase (maximum voltage) will produce a minimum inrush current value with a value an average of $0.74 \mathrm{~A}$ in phase $\mathrm{R}, 3.41 \mathrm{~A}$ in phase $\mathrm{S}$ and 3.80 $\mathrm{A}$ in phase $\mathrm{T}$.

2. In designing a pre energize component the main thing to note is the magnitude of the magnetization inductance $\left(L_{m}\right)$ value of a transformer. If the magnetization inductance value of a transformer is unknown (the absence of manufacturer data) a calculation assumption can be made to obtain the magnetization inductance value of a transformer that has been discussed in this study.

3. The inrush current value in each test always shows a lower value for the test transformer which is given initial flux compared to that which is energized without any initial DC flux. The difference in the reduction of the inrush current for each phase and each ignition angle is in the range $1.48 \mathrm{~A}-28.22 \mathrm{~A}$ Giving a DC flux initially by using a pre energize component in the form of a charged capacitor and then discharged to the $\mathrm{S}$ and $\mathrm{T}$ phase of the transformer is proven to reduce the amount of inrush current seen from the testing that has been done.

4. Flux in the transformer before energizing affects the magnitude of the inrush current which is divided. If the flux in the transformer core is not in accordance with the steady state conditions then the generated inrush current may be of high value. Meanwhile, if the flux contained in the transformer core is close to or equal to the value of the flux at steady state inrush currents generated will be low value. The pre energize component helps initiate the initial flux in the transformer to approach the flux under steady state conditions. 
5. Based on the tests conducted the pre energize method will work optimally when the ignition angle is 90 degrees, because the resulting inrush current is the smallest, with an average of $0.74 \mathrm{~A}$ in phase $\mathrm{R}, 3.41 \mathrm{~A}$ in phase $\mathrm{S}$ and $3.80 \mathrm{~A}$ in phase $\mathrm{T}$. At angle 0 degree, the inrush current value is still high enough for phase $\mathrm{R}$ with an average value of $31.36 \mathrm{~A}$. While at an angle of 60 the inrush current is still high for phase $\mathrm{T}$ with an average of $10.7 \mathrm{~A}$.

\section{REFERENCES}

[1] N. Chiesa, Power Transformer Modeling for Inrush Current Calculation. Trondheim: Norwegian University of Science and Technology, 2010.

[2] S. V. Kulkarni and S. A. Khaparde, Transformer engineering: design and practice. New York: Marcel Dekker, Inc, 2004.

[3] B. Poulin, R. Del Vecchio, P. Feghali, R. Ahuja, and D. Shah, Transformer Design Principles: With Applications to Core-Form Power Transformers. CRC Press, 2001.

[4] M. P. J. Kotak and A. Thakur, "INRUSH CURRENT REDUCTION IN THREE PHASE POWER TRANSFORMER BY USING PREFLUXING TECHNIQUE," vol. 5, no. 10, p. 10.

[5] S. J. Chapman, Electric machinery fundamentals, 4th ed. New York, NY: McGraw-Hill Higher Education, 2005.

[6] J. Winders, Power Transformers: Principles and Applications, vol. 17. CRC Press, 2002.

[7] N. Chen, C. Wang, J. Zhang, F. Yang, Y. Chen, and W. Hong, "The inrush current analysis and restraining method of energizing no-load transformer," in $20163 \mathrm{rd}$ International Conference on Systems and Informatics (ICSAI), Shanghai, China, 2016, pp. 204-207.

[8] S. A. M. Mirkalaei and F. Hashiesh, "Controlled switching to mitigate power transformers inrush current phenomenon," in 2015 50th International Universities Power Engineering Conference (UPEC), Stoke On Trent, United Kingdom, 2015, pp. 1-4.

[9] A. Reis, J. C. de Oliveira, R. Apolonio, and H. S. Bronzeado, "A controlled switching methodology for transformer inrush current elimination: Theory and experimental validation," in 11th International Conference on Electrical Power Quality and Utilisation, Lisbon, Portugal, 2011, pp. 1-6.

[10] M. P. J. Kotak and J. Singh, "Prefluxing Technique to Mitigate Inrush Current of Three-Phase Power Transformer," vol. 4, no. 6, p. 7, 2013.

[11] D. I. Taylor, J. D. Law, B. K. Johnson, and N. Fischer, "Single-Phase Transformer Inrush Current Reduction Using Prefluxing," IEEE Trans. Power Deliv., vol. 27, no. 1, pp. 245-252, Jan. 2012. 